\title{
Correction of a brow ridge deformity in a comminuted depressed skull fracture using a multiple-layered pericranial flap: the Persian carpet method
}

\author{
Daiwon Jun, Jin Kwan Kim, \\ Young Chul Suh, Young Jin Kim \\ Department of Plastic and Reconstructive \\ Surgery, Bucheon St. Mary's Hospital, \\ College of Medicine, The Catholic \\ University of Korea, Bucheon, Korea
}

The authors would like to thank Sammy Jun for an artistic illustration of the Persian carpet method.
Frontal sinus fractures are common traumatic injuries of the head and neck, accounting for $8 \%$ of facial fractures. When a severe frontal sinus fracture and a naso-ethmoidorbital fracture occur together, a postoperative contour deformity is highly likely. A pericranial flap is a reliable and versatile tool for craniofacial reconstruction. The authors fabricated an anteriorly-based pericranial flap in multiple layers to camouflage the fracture site and augment the brow ridge for volumization. Open reduction and pericranial flap coverage using this method (dubbed the "Persian carpet" method) were successfully performed in a 26-year-old male patient with a comminuted frontal bone fracture and a naso-ethmoid-orbital fracture.

Keywords Frontal sinus / Reconstructive surgical procedure / Skull fracture

\section{INTRODUCTION}

Frontal sinus fractures are common traumatic head and neck injuries that account for $8 \%$ of facial fractures [1]. Although there is no consensus regarding the ideal method of managing frontal sinus fractures, generally accepted indications for open reduction include a depressed anterior wall fracture, a displaced posterior wall fracture, or a nasofrontal duct injury [2]. Herein, we describe the treatment of a patient with a combined comminuted depressed skull fracture (FCCD) and naso-ethmoid-orbital (NEO) fracture that required open reduction. Since every component of the nasofrontal angle had been violated, accurate reduction based on adjacent bony landmarks was challenging, and a certain degree of postoperative deformity was anticipated. The authors devised a method

Received: Dec 22, 2020 Revised: Mar 16, 2021 Accepted: Apr 21, 2021 Correspondence: Young Jin Kim Department of Plastic and Reconstructive Surgery, Bucheon St. Mary's Hospital, College of Medicine, The Catholic University of Korea, 327 Sosa-ro, Wonmi-gu, Bucheon 14647, Korea Tel: +82-32-340-7059, Fax: +82-32-340-2544, E-mail: psyjkim@catholic.ac.kr Copyright @ 2021 The Korean Society for Aesthetic Plastic Surgery.

This is an Open Access article distributed under the terms of the Creative Commons Attribution Non-Commercial License (https://creativecommons.org/licenses/by-nc/4.0/) which permits unrestricted non-commercial use, distribution, and reproduction in any medium, provided the original work is properly cited. $\quad w w w . e-a a p s . o r g$ for reconstructing the frontal bone and correcting the contour deformity using a pericranial flap.

\section{CASE REPORT}

Preoperative computed tomography imaging of a 26-year-old male patient revealed an FCCD with NEO fracture resulting in a severe depression of the forehead (Fig. 1). An open coronal approach through the subgaleal plane was performed. The integrity of the pericranial layer was preserved. Following the coronal flap dissection, an anteriorly-based pericranial flap was elevated in a conventional manner. The width of the flap was designed to encompass the total length of both brows, and the length was designed from the start of the coronal incision, thereby maximizing the size of the flap that could be harvested. Reduction of the fractured frontal bone was completed with the insertion of an absorbable mesh plate (Resorb X; KLS Martin, Freiburg, Germany). The pericranial flap was folded in multiple layers with a width corresponding to the desired volume of the brow ridge (Fig. 2) and then fixed to the adjacent tissue with 5-0 Vicryl sutures. The folded pericranial flap along the brow ridge resembled a folded carpet for exhibition (Fig. 3). After reducing the facial fracture and applying the pericranial flap through this method (dubbed the "Persian carpet" method), an adequate forehead contour and brow volumization were achieved (Fig. 4). 


\section{DISCUSSION}

The utility of pericranial flaps has been proven in a wide range of craniofacial reconstructions. Pericranial flaps are commonly used
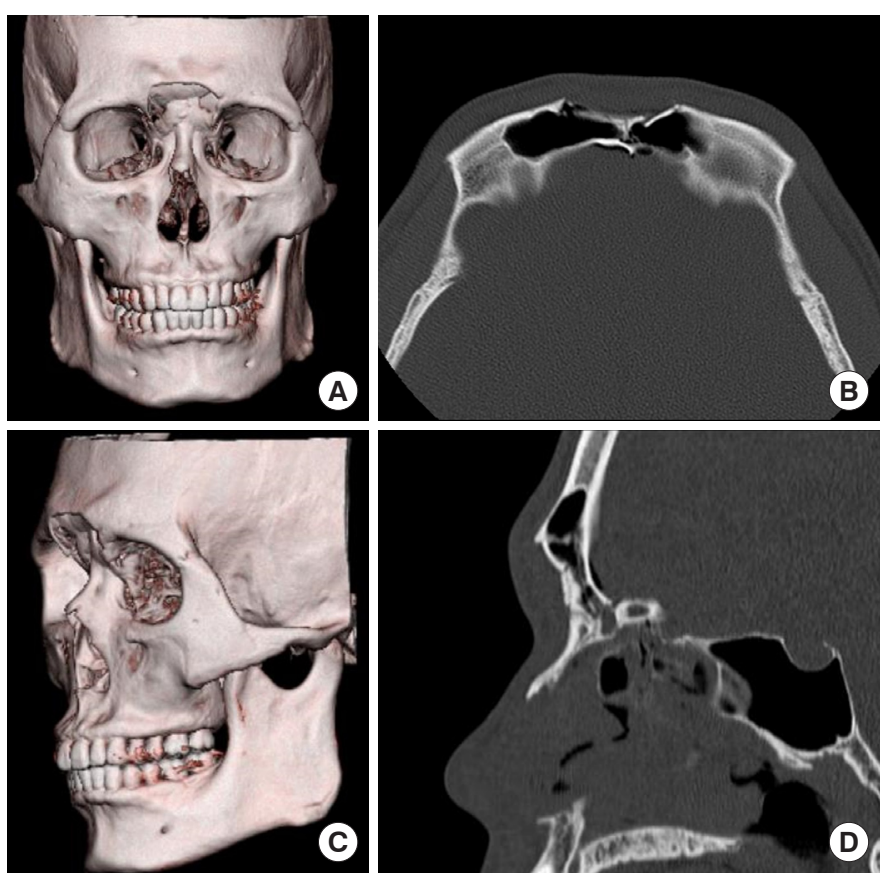

Fig. 1. Preoperative computed tomography imaging revealed a comminuted frontal bone fracture with a naso-ethmoid-orbital fracture resulting in severe depression of the frontal bone contour $(A, C)$. The posterior tables of both frontal sinuses were spared $(B, D)$. for skull base reconstruction and cranialization or obliteration of the frontal sinus [3]. Their reliability is based on a robust blood supply from the supratrochlear and supraorbital arteries when anteriorly based [4]. As documented in numerous published reports, the versatile range of pericranial flaps spans from treating frontal sinus fractures to reconstructing the ear, forehead, orbit, and nose [5]. The most widely established use of pericranial flaps in craniofacial surgery is for obliteration of the frontal sinus. An anteriorly based flap is raised and folded into the entire sinus cavity to seal it off from the nasal cavity [6]. Nonetheless, the mainstay of pericranial flap usage relies upon the length and abundant volume of these flaps. Numerous studies have described the use of pericranial flaps in diverse situations, and have reported folding the flaps to achieve

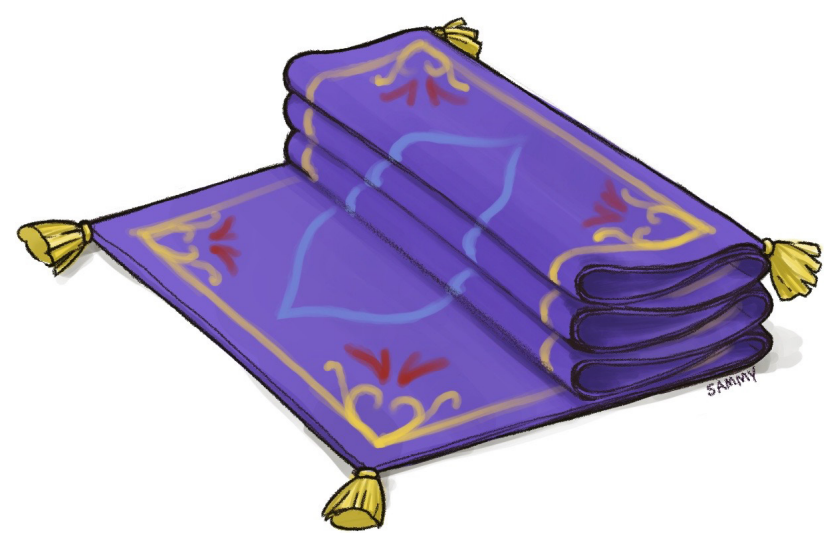

Fig. 3. An illustration of a folded Persian carpet. The Persian carpet method received its name because of the resemblance of the pericranial flap folded in multiple layers to stacked carpets on sale.
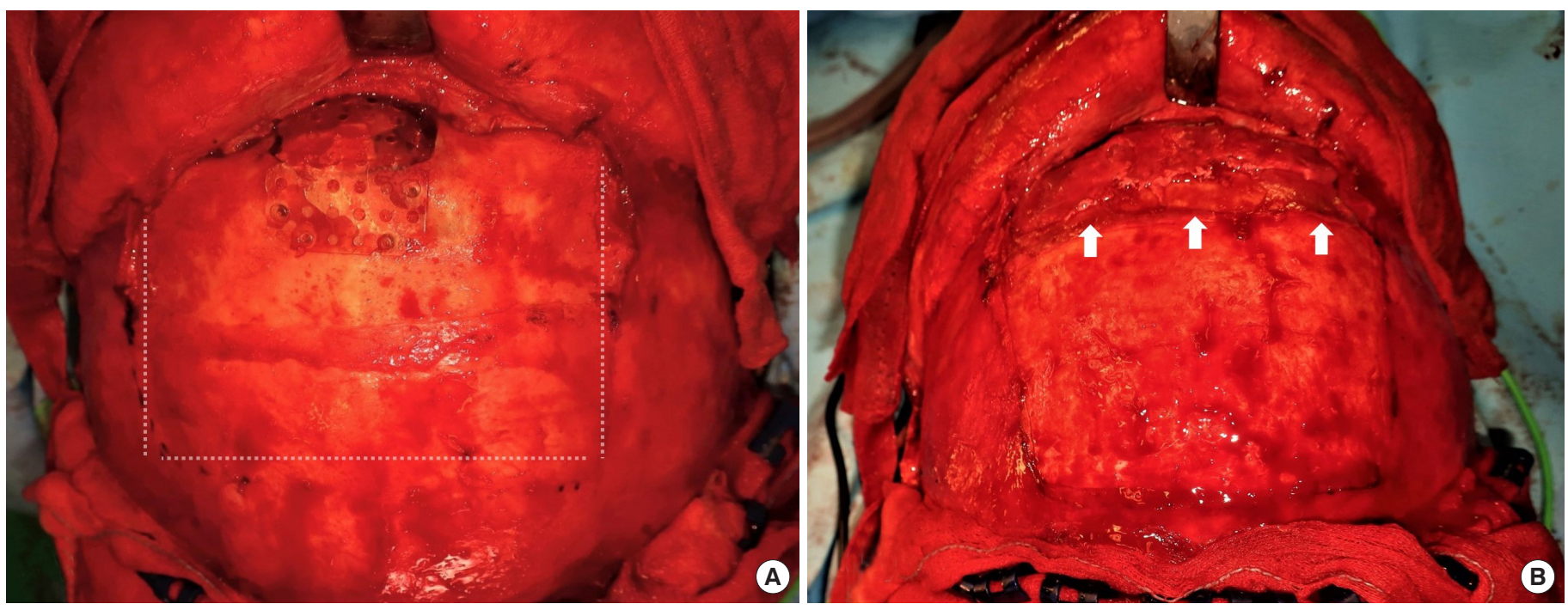

Fig. 2. Intraoperative photographs of elevation and application of the pericranial flap. Frontal bone reconstruction was performed using an open coronal approach. A pericranial flap was elevated and reflected with a coronal flap (A). The margin of the anteriorly based pericranial flap is marked using dots. The pericranial flap was applied using the Persian carpet method (B). The Persian carpet flap is indicated with white arrows. 

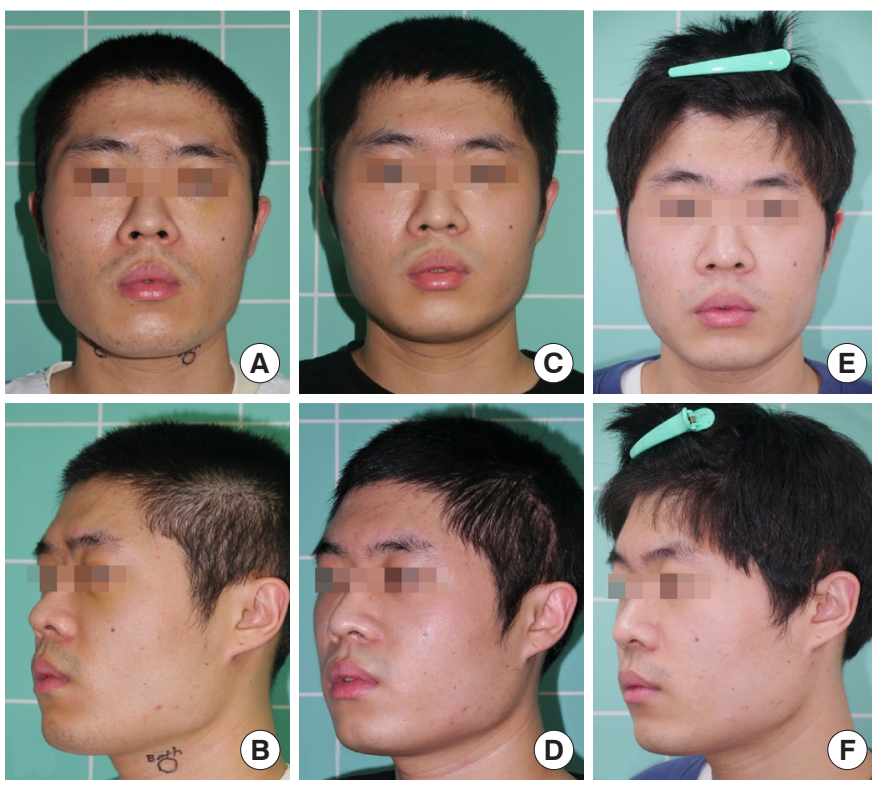

Fig. 4. Clinical photographs of the patient before and after the operation. Photographs of the preoperative state $(A, B), 6$ months after surgery (C, D), and 12 months after surgery (E, F) were taken. The nasofrontal angle and brow volume were preserved.

sufficient bulk. However, no previous studies have focused on augmenting the brow ridge, which is commonly violated after frontal sinus fractures.

The authors believe that the present method can be applied to patients with complex frontal sinus fractures without the need for obliteration. Optimal bony reduction will result in an inadequate restoration. However, when a combined FCCD and NEO fracture occurs, accurate reduction is not always achievable. In particular, if the patient strongly prioritizes aesthetic outcomes after surgery, an ancillary method for brow augmentation is required. The authors' focus was to restore the nasofrontal angle and enhance the brow line. Using the Persian carpet method, the authors could accurately tailor the width of the flap to fit the patient's brow line. Camouflage of the inserted implant and fracture site was achieved, as well as augmentation of the brow ridge with adequate volumization. Furthermore, the flap could be elevated during the reduction procedure, so no additional donor site was required. Since an anteriorly based vascular flap was used, preservation of the original volume is predicted. The primary limitation of this study is that the method has been applied in only one case. However, based on our observations, the Persian carpet method can be used to overcome the risk of facial deformity in patients with compound facial fractures, including combined FCCD and NEO fractures.

\section{NOTES}

\section{Conflict of interest}

No potential conflict of interest relevant to this article was reported.

\section{Ethical approval}

The Institutional Review Board of the Bucheon St. Mary's Hospital exempted this work from any need for formal approval (IRB exemption number: HC20ZASI0087). The study was conducted in accordance with the principles of the Helsinki Declaration.

\section{Patient consent}

The patient provided written informed consent for the publication and use of his images.

\section{ORCID}

Daiwon Jun

Jin Kwan Kim

Young Chul Suh

Young Jin Kim

\author{
https://orcid.org/0000-0003-4713-333X \\ https://orcid.org/0000-0003-3404-950X \\ https://orcid.org/0000-0002-0320-3933 \\ https://orcid.org/0000-0002-9046-9907
}

\section{REFERENCES}

1. Montovani JC, Nogueira EA, Ferreira FD, et al. Surgery of frontal sinus fractures: epidemiologic study and evaluation of techniques. Braz J Otorhinolaryngol 2006;72:204-9.

2. Yavuzer R, Sari A, Kelly CP, et al. Management of frontal sinus fractures. Plast Reconstr Surg 2005;115:79e-93e.

3. Thaller SR, Donald P. The use of pericranial flaps in frontal sinus fractures. Ann Plast Surg 1994;32:284-7.

4. Potparic Z, Fukuta K, Colen LB, et al. Galeo-pericranial flaps in the forehead: a study of blood supply and volumes. Br J Plast Surg 1996; 49:519-28.

5. Argenta LC, Friedman RJ, Dingman RO, et al. The versatility of pericranial flaps. Plast Reconstr Surg 1985;76:695-702.

6. Wolfe SA. The utility of pericranial flaps. Ann Plast Surg 1978;1:14753. 